\title{
Cytotoxicity of urethane dimethacrylate composites before and after aging and leaching
}

\author{
N. M. Mohsen, R. G. Craig, C. T. Hanks \\ Department of Biologic and Materials Sciences, Bioengineering Program and the School of Dentistry, The University of \\ Michigan, Ann Arbor, Michigan 48109-1078
}

Received 21 May 1996; accepted 13 February 1997

\begin{abstract}
The in vitro cytotoxicity of urethane dimethacrylate composites cured at different times by visible light and after different aging times and extraction treatments was evaluated using succinic dehydrogenase activity in the mitochondria of a fibroblastic cell line to reflect cell viability. In addition, extractable chemicals associated with cell response were identified. The composite samples were tested untreated, polished, or extracted with water or $75 \%$ ethanolwater. Balb/c 3T3 fibroblasts were used as the cell culture system while MTT-formazan production was used as the toxicity parameter. Cell viability was calculated as a percentage of Teflon controls. Identification of the chemicals was measured by extracting the composites with $75 \%$ ethanolwater, separating the extract by HPLC, and identifying the fractions with mass spectroscopy. In general, cell viability increased continuously with curing time for differently treated samples at high aging times (288 h) while it decreased when the composites were not aged $(0 \mathrm{~h})$. In addition, for $75 \%$ ethanol or water-extracted composites, cell viability increased within the first $24 \mathrm{~h}$ of aging and reached a plateau after $72 \mathrm{~h}$. Lowest cytotoxicity occurred when the samples were extracted with the $75 \%$ ethanol solution. The
\end{abstract}

highest cytotoxic effects were found when the samples were untreated. Slightly reduced cytotoxic effects were seen with polished composites. The results suggest that curing the light-activated composites for a minimum of $150 \mathrm{~s}$ and postcuring for $24 \mathrm{~h}$ is required to attain comparable biocompatibility with the Teflon control. Removing the oxygeninhibited layer from these composites decreased the cytotoxicity by $33 \%$ while extracting the composites with $75 \%$ ethanol-water decreased it by $77 \%$. Chemicals released from the surface accounted for approximately $40 \%$ of cellular response while about $60 \%$ of the response was due to chemical components released from the bulk. The primary leachable component from the composites was UDMA monomer. Small quantities of 1,6 hexane diol methacrylate, camphoroquinone, and 2,4,6-tritertiarybutyl phenol also were found. (C) 1998 John Wiley \& Sons, Inc. J Biomed Mater Res, 39, 252-260, 1998.

Key words: cytotoxicity of UDMA composite; curing time of UDMA and cytotoxicity; effect of extraction of UDMA on cytotoxicity; aging of composites and cytotoxicity; extractable chemicals from UDMA composite

\section{INTRODUCTION}

Visible light-cured dental composites result in restorations in which the organic phase is not completely polymerized. The unreacted components may result from the attenuation of the radiation by the composite or from inadequate intensity or length of exposure to radiation. ${ }^{1}$ Also, the presence of oxygen inhibits polymerization, resulting in a higher percentage of unreacted components at the surface than in the bulk.

Incomplete polymerization not only causes a decrease in the mechanical properties, but it can invoke

Correspondence to: R. Craig

Contract grant sponsor: National Institutes of Health; Contract grant number: P50 DE 09296

(C) 1998 John Wiley \& Sons, Inc. CCC 0021-9304/98/020252-09 tissue reactions, as shown by Spangberg et al. ${ }^{2}$ Also, Anderson and associates ${ }^{3}$ demonstrated that the combination of different components of composites elicited cytotoxic response in in vitro cell culture and suggested that components of unpolymerized resin may leach from restorations and exert a severe cytotoxic response. In a later study (Anderson et al. ${ }^{4}$ ) it was proposed that bacterial microleakage might be the primary cause of pulpal inflammation.

In support of the proposal that unpolymerized chemicals from composites cause pulpal inflammation. Tobias and associates ${ }^{5}$ found that a significant inflammatory pulpal response was elicited from a composite resin when it was used without a cavity liner, and they attributed the response to toxic ingredients. Hanks et al. ${ }^{6}$ proposed that the toxicity of composites could be caused either by products from an incomplete reaction or by new toxic products that result from the setting reaction. Caughman and cowork- 
$\mathrm{ers}^{7}$ stated that the degree of cytotoxicity of lightcured composites was inversely related to curing time and that the degree of tissue reaction was a function of the degree of polymerization, percentage of filler, and cell type. Later Rathbun et al. ${ }^{8}$ showed that a $90 \%$ reduction of cytotoxicity in cell culture was attained when the leachable components were extracted from a Bis-GMA composite. Although it had been shown in a 21-day animal study on monkeys that most components of composites were not significantly irritating to the pulp, 2-hydroxy-4 methoxy-benzophenone, methyl ester of benzoin, and methyl peroxide were toxic in deep-cavity preparations in the absence of bacteria. $^{9}$

In support of the claim that bacteria from leakage around composites are the main cause of pulpal irritation, Brännström and associates ${ }^{10}$ reported that bacteria were a more serious threat than chemicals to pulpal irritation. Inokoshi et al. ${ }^{11}$ concluded that microleakage of bacteria was responsible for most of pulpal irritation since a greater response was found when no etching of tooth structure was done, resulting in poor bonding. Also, Cox et al. ${ }^{12}$ reported that pulpal inflammation in monkeys is associated with bacterial contaminants and claimed they are more significant pulpal irritants than chemicals. Thus it is presently believed that pulpal response to composites is a combination of bacterial microleakage and diffusion of unpolymerized components.

In the clinical use of UDMA composites, they may be polymerized directly in the mouth in a retentive cavity preparation for various times using visible light. Or, they may be partially polymerized in the mouth in a nonretentive cavity preparation and then removed and postcured at an elevated temperature before being cemented to the tooth. The surface of the polymerized composite may or may not be polished depending on whether the surface is overcontoured. Finally, most studies evaluating extractable components from composites have used organic solvents rather than water to simulate saliva because of the more rapid rate of extraction. In addition, Ferracane and Condon showed that $75 \%$ of the leachable components from a dental composite were eluted into an ethanol/water mixture within a $3 \mathrm{~h}$ period. $^{13}$

Using a standard cell line, this study investigated the effect of curing and postcuring times of UDMA composites on cytotoxicity, both initially and after aging, by extracting with water, to simulate saliva and with a $75 \%$ ethanol-water solution to accelerate extraction. The effect on its cytotoxicity of polishing the composite also was investigated. Finally, extracts were tested to identify the compounds that may be associated with the cytotoxicity of the composites.

\section{METHOD AND MATERIALS}

\section{Composite system}

Urethane dimethacrylate (UDMA, Esschem Co., Essington, PA) was used as a monomer system. Zirconia-silica (ZS, 3M Dental Products, St. Paul, MN) with a surface area of 1.6 $\mathrm{m}^{2} / \mathrm{g}$ and an average diameter of $1.5 \mu \mathrm{m}$ (3M Dental Products, St. Paul, MN) was used as a filler. 3-methacryloxypropyltrimethoxysilane (MAPM, Huls America, Piscataway, NJ, formerly Petrarch Systems, Bristol, PA) was used to silanate the filler for coupling to the resin.

\section{Sample preparation}

The filler was silanated as described by Mohsen and Craig ${ }^{13}$ by depositing the silane from an aqueous solution of $75 \%$ ethanol (190 proof) and 25\% silane (weight ratio). The amount of silane used for the filler treatment in this part of the study was three times $(3 \times)$ the minimum uniform coverage. ${ }^{14}$ The polymer was formulated from UDMA using a dl-camphoroquinone (CQ) catalyst and a 2-dimethylaminoethylmethacrylate (DMAEMA) accelerator in concentrations described by Douglas, Craig, and Chen. ${ }^{15}$ Composites were formulated from UDMA zirconia-silica and MAPMsilanated zirconia-silica using the accelerator and the catalyst.

The mixed composite paste was placed in Teflon diskshaped molds (6.0-mm diameter and $3.5-\mathrm{mm}$ thick). Teflon controls were punched out in a similar shape and dimension. The composite paste was made in two layers and each cured by visible light in a TRIAD II oven (Dentsply International, York, PA) for 13, 30, 90, 150, and $300 \mathrm{~s}$ at room temperature. The samples were then aged for $0,24,72,144,216$, and $288 \mathrm{~h}$ at $57^{\circ} \mathrm{C}$ (a typical temperature for postcuring composites for use in the indirect procedure) in a vacuum oven. Immediately after being cured and aged, the samples were weighed on an analytical balance (initial weight). For each curing and aging condition, the samples were either untreated, polished, or extracted with different solvents. Polishing of the samples was carried out by polishing each side with 600 grit silicon carbide paper and then smoothing both sides with 1200 grit silicon carbide paper. Extraction of the samples was carried out by placing them in vials containing $10 \mathrm{~mL}$ of either distilled water or a mixture of $75 \%$ ethanol/ water (volume ratio), representing poor and good solvents, respectively, for composites. The samples were extracted for $48 \mathrm{~h}$ at ambient temperatures since it was found by Ferracane and Condon ${ }^{13}$ that elution of nearly all the leachable components was complete within the first $24 \mathrm{~h}$ period in either solvent. After the different treatments, all samples and controls were ultrasonically cleaned, rinsed thoroughly in double-distilled, deionized water and dried to a constant weight for 8-12 $\mathrm{h}$ in a vacuum desiccator (dry weight). Six replicates at five curing times, six aging times, and four conditions (untreated, polished, water extracted, and ethanol-solution extracted) resulted in 720 samples evaluated for cytotoxicity. 
For identification of leachables, the UDMA-based composites were extracted using the mixture of $75 \%$ ethanol/ water. The composite paste was transferred to the Teflon molds, and disks were made in two layers. Each layer was cured by the visible light for $30 \mathrm{~s}$. The various composites then were aged for up to $288 \mathrm{~h}$. The polymerized samples were ground with a mortar and pestle to maximize the surface area for extraction. The ground composite powder was weighed and placed in $10 \mathrm{~mL}$ of either solvent at ambient temperature for $48 \mathrm{~h}$. The solvent was pipetted out and replaced with $5 \mathrm{~mL}$ of fresh solvent, and the powder was extracted for an additional $24 \mathrm{~h}$. Throughout the extraction process, the vials were covered to prevent solvent evaporation and were kept in a light-free environment. After the third day, the vials were uncovered, and the solvent was removed and combined with the older extract (total of 15 $\mathrm{mL}$ ). The powder then was weighed after it was vacuum dried for $48 \mathrm{~h}$ at $80^{\circ} \mathrm{C}$.

The resultant extract first was quantified by evaporating the solvent at ambient temperature and pressure. Three replicates of powder extraction were made to quantify the amount of extract while one replica was used to identify the leachables.

\section{Cell culture}

All samples, cured and aged for different times and then untreated, extracted, or polished, as well as Teflon controls were centered in 24-well dishes of polystyrene (Costar, Cambridge, MA). Teflon holders were made to hold the samples in place. Then the wells were plated with Balb/c 3T3 embryonic mouse fibroblasts derived from clone A31 (CCL 163: anchorage-dependent, aneuploid, and contact-inhibited mouse fibroblasts; ATCC, Rockville, MD). Fibroblasts of this standard cell line were used rather than primary cell cultures such as human gingival fibroblasts because there is much less variation in their behavior when testing for early biocompatibility events, such as cytotoxicity.

The medium used consisted of Dulbecco's minimum essential medium (DMEM), 3\% Nu-Serum (Collaborative Research, Bedford, MA), 28 mM HEPES (N'-2-hydroxy-ethylpiperazine- $\mathrm{N}^{\prime}$-2-ethane-sulfonic acid, $\left.\mathrm{pH}=7.2\right)$, and supplements $(2 \mathrm{mmol} / \mathrm{L}$ glutamine, 125 units $/ \mathrm{mL}$ penicillin, 125 $\mu \mathrm{g} / \mathrm{mL}$ streptomycin, and $10 \mu \mathrm{g} / \mathrm{mL}$ gentamycin; Gibco, Grand Island, NY). HEPES buffer was added to control the $\mathrm{pH}$ of the medium.

The stock cells were grown to confluency and were treated for $4 \mathrm{~min}$ at $37^{\circ} \mathrm{C}$ with a sterile trypsin/EDTA solution consisting of $0.05 \%$ trypsin and $0.02 \%$ EDTA in phosphate-buffered silane (PBS) to harvest the cells. After trypsinization, cells were collected by centrifugation at $750 \mathrm{rpm}$ for $4 \mathrm{~min}$, resuspended in cell culture medium, and diluted with medium so that the plating concentration was 25,000 cells $/ \mathrm{cm}^{2}$. The cells were added in $0.5 \mathrm{~mL}$ of medium to each culture well of the 24 -well dish that contained the sample. Care was taken to make sure that the cell suspension would cover the area around the sample evenly. The dishes were incubated at $37^{\circ} \mathrm{C}$ with $95 \%$ air, $5 \% \mathrm{CO}_{2}$, and $85 \%$ relative humidity for $48 \mathrm{~h}$, followed by processing. Cytotoxicity was calculated as a percent of the Teflon control. Six replicate wells were used for each composite/condition tested. Analysis of variance (ANOVA) for a general factorial design was used to determine whether the effects of resin-aging and curing times on the different treatments were significant at the $95 \%$ confidence level.

\section{Measurements of cytotoxicity}

To test for cytotoxicity, MTT-formazan production was used to evaluate succinic dehydrogenase enzyme activity in the mitochondria of the cells, which is a reflection of cell metabolism and, in exponentially growing cells, cell number. The medium was suctioned off, and the cells were washed with PBS. One-half $\mathrm{mL}$ of histochemical staining/ disodium succinate medium was added to each well and was incubated for $90 \mathrm{~min}$ at $37^{\circ} \mathrm{C}$. This medium consists of $10 \mathrm{~mL}$ of $2.5 \mathrm{~mL}$ molal disodium succinate with $90 \mathrm{~mL}$ of the dye solution containing $100 \mathrm{mg}$ MTT, $25 \mathrm{~mL}$ of $0.2 \mathrm{M}$ Tris$\mathrm{HCl}, 10 \mathrm{~mL}$ of $0.005 \mathrm{M} \mathrm{MgCl}_{2}, 5.0 \mathrm{~mL}$ of $0.05 \mathrm{M} \mathrm{CoCl}_{2}, 55 \mathrm{~mL}$ of $\mathrm{H}_{2} \mathrm{O}$, and $80 \mu \mathrm{L}$ of $10 \mathrm{~N} \mathrm{HCl}$. After the incubation,the staining medium was suctioned off, and the cells were fixed in Tris-HCl-buffered $4 \%$ formalin for $5 \mathrm{~min}$, rinsed twice with distilled water, and dried in air. To dissolve the formazan dye, $0.5 \mathrm{~mL}$ of $6.25 \% \mathrm{v} / \mathrm{v} 0.1 \mathrm{~mol} / \mathrm{L} \mathrm{NaOH}$ in dimethylsulfoxide (DMSO) was added to each well. The amount of formazan was quantified by measuring its optical density at $560 \mathrm{~nm}$, and the data were expressed as means and standard deviations for the six replications.

\section{Identification of leachables}

High performance liquid chromatography (HPLC) was used to separate samples of the extract, UDMA monomer, and the UDMA mixed with the initiator and catalysts at ambient temperatures. The HPLC unit was a Rainin High Performance Liquid Chromatographer with an ultra detector set at $220 \mathrm{~nm}$. The samples were diluted with $0.1 \%$ TFA in $80 \% \mathrm{CH}_{3} \mathrm{CN}$. The solution was injected into a $\mathrm{C} 183.9 \times$ $300 \mathrm{~mm}$ (Waters, Millipore, Bedford, MA) column at a flow rate of $1 \mathrm{~mL} / \mathrm{min}$ and sampling interval of $0.1 \mathrm{~s}$ for $60 \mathrm{~min}$.

Mass spectroscopy (MS) with a direct probe was used to analyze the most intense fractions of the extract. The fractions were dried to a constant weight prior to analysis.

\section{RESULTS}

\section{Evaluation of cytotoxicity}

The effects of different curing and aging times for the composites on cytotoxicity are shown in Figures $1-4$. The percent metabolism relative to Teflon control for Balb/c 3T3 cells for untreated, polished, ethanol-, and water-extracted composites, respectively, are 


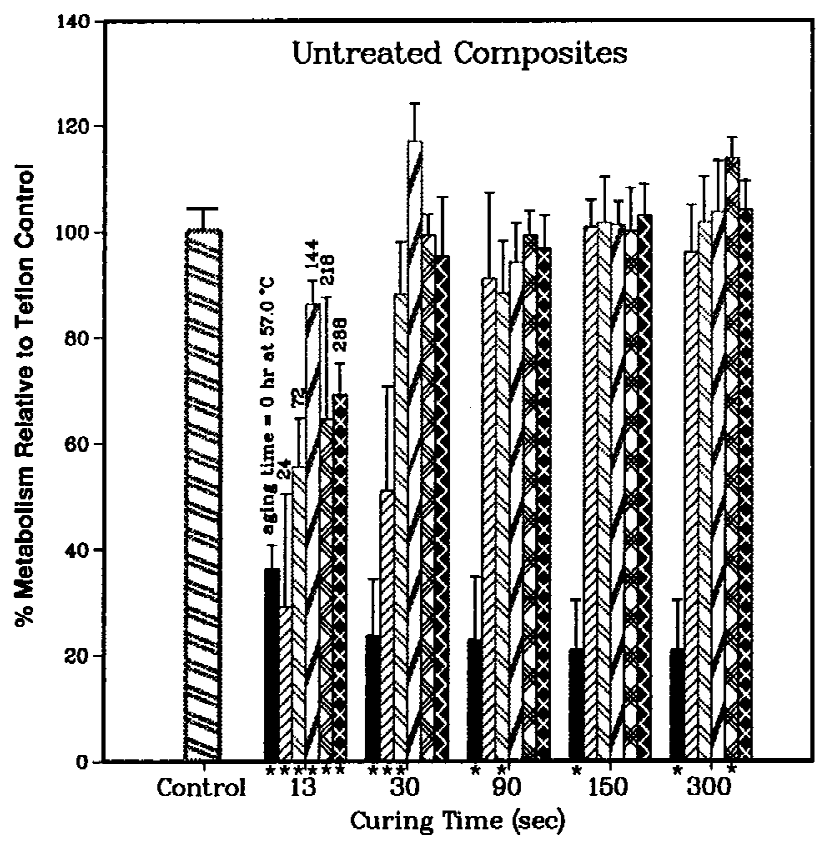

Figure 1. Percent metabolism relative to Teflon control for Balb/c 3T3 cells around aged UDMA-based composites as a function of different curing times.

given for the cells exposed to composites that were light cured for $13-300 \mathrm{~s}$ and aged for $0-288 \mathrm{~h}$ at $57^{\circ} \mathrm{C}$. In these figures, error bars represent one standard deviation and asterisks indicate samples significantly different from control at $p=0.05$. The effect of curing time of the treated and untreated composites on the cell metabolism was shown to be statistically signifi-

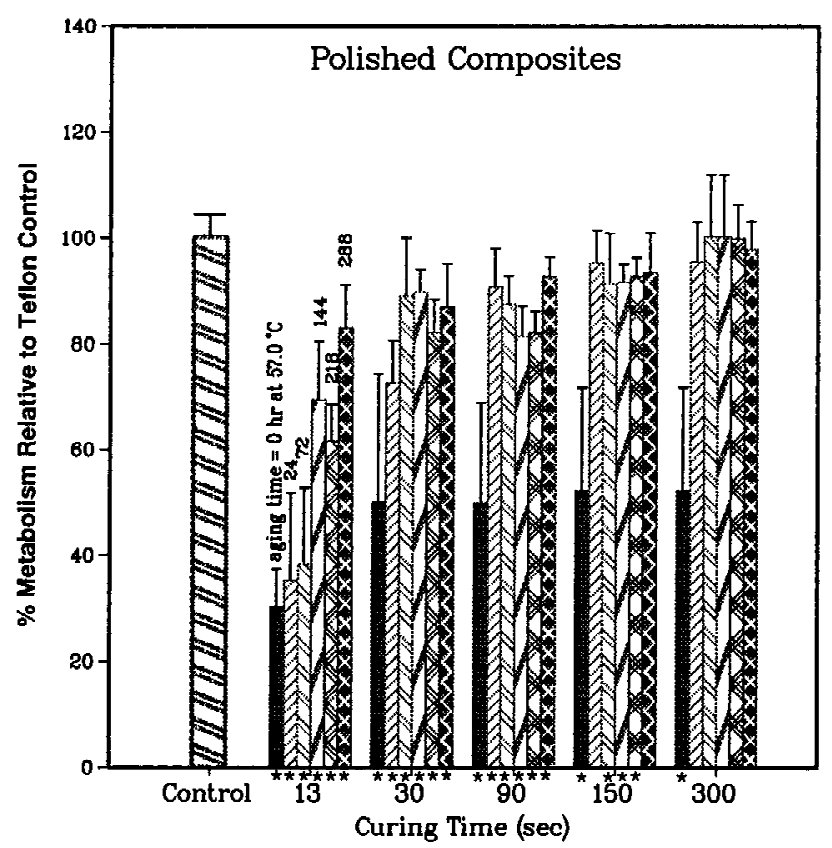

Figure 2. Percent metabolism relative to Teflon control for Balb/c 3T3 cells around aged polished UDMA-based composites as a function of different curing times.

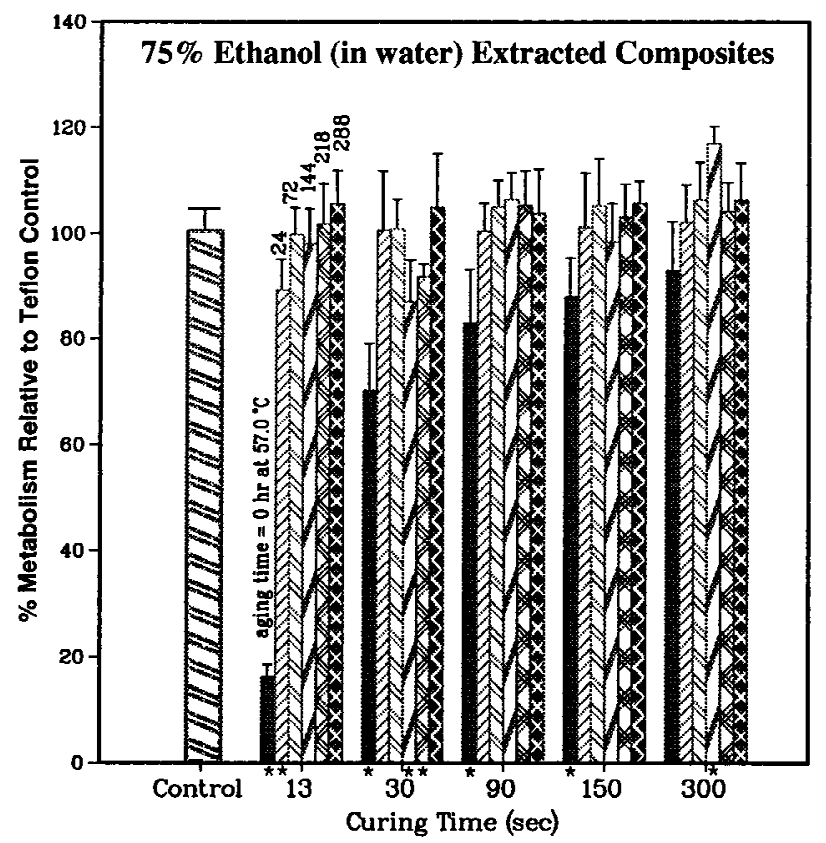

Figure 3. Percent metabolism relative to Teflon control for Balb/c 3T3 cells around aged 75\% ethanol-water extracted UDMA-based composites as a function of different curing times.

cant $(p=0.05)$. Cell metabolism generally increased with curing time and reached values of $104.1(5.4) \%$, $97.9(5.2) \%, 106.2(7.4) \%$, and $106.6(7.2) \%$ of the Teflon control for untreated, polished, ethanol- and waterextracted composites, respectively, when samples were aged for $288 \mathrm{~h}$. However, the increases were not as noticeable with ethanol-extracted composites, espe-

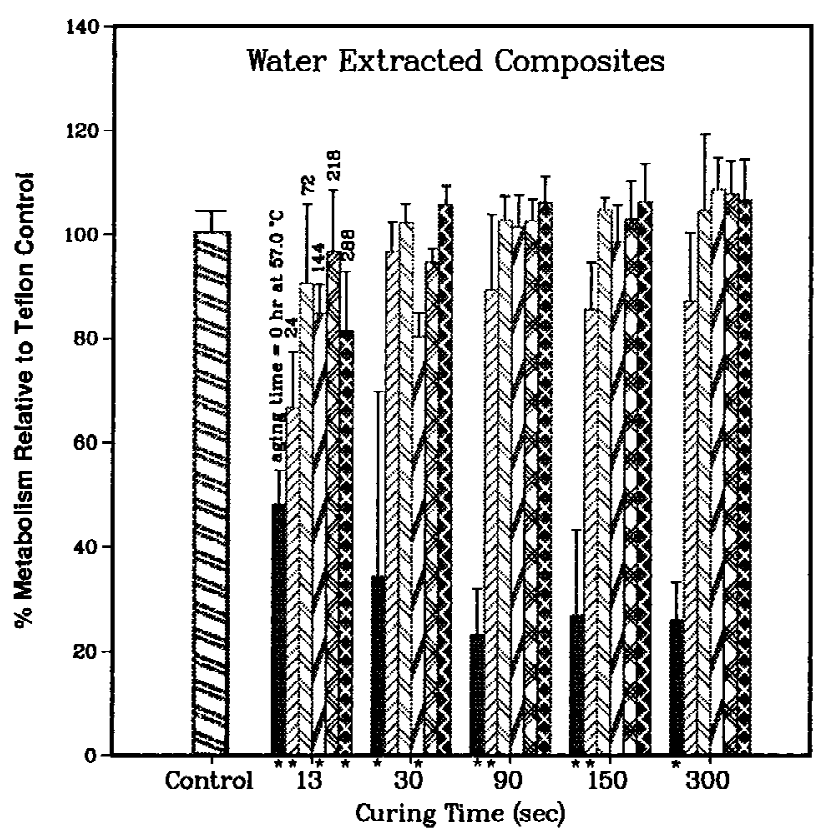

Figure 4. Percent metabolism relative to Teflon control for $\mathrm{Balb} / \mathrm{c}$ 3T3 cells around aged water-extracted UDMA-based composites as a function of different curing times. 
cially at the longer aging times. When the composites were not aged at $57^{\circ} \mathrm{C}$, the metabolism of the cells was either worse (for untreated or water-extracted) or did not improve as much (for polished or ethanol-treated) with increasing curing times.

The effects of different aging times $\left(57^{\circ} \mathrm{C}\right)$ of composites on the percent metabolism for the cells also are shown in Figures 1-4. ANOVA showed that the effect on cell metabolism when exposed to composites that were aged for different times was statistically significant $(p=0.05)$. There was an increase in cell metabolism as compared to non-aged composites within the first $24 \mathrm{~h}$ of aging except with untreated composites. Composites cured from 30-300 s reached a plateau for metabolism after $72 \mathrm{~h}$ when the cells were exposed to the $75 \%$ ethanol-water-extracted composites. The increase in cell metabolism with aging was more gradual when the composites were cured for $13 \mathrm{~s}$ because of the low conversion and reached control levels only with the $75 \%$ ethanol-water-extracted composites.

Finally, ANOVA showed there was a statistical difference $(p=0.05)$ among the different treatments on cell metabolism. Except for composites cured for $13 \mathrm{~s}$ and aged $0 \mathrm{~h}$, ethanol-extracted composites had the lowest toxic effects on the cells. Polishing had variable effects on composites cured for $13 \mathrm{~s}$ but had much better effects on composites cured for $300 \mathrm{~s}$. Composites cured for $300 \mathrm{~s}$ and aged for $24 \mathrm{~h}$ increased cell metabolism to about $95 \%$ and decreased the difference between ethanol- and water-extracted samples as well as unpolished and polished samples, and further aging improved metabolism only slightly. Waterextracted composites had lower toxic effects on the cells than the untreated composites when the composites were cured for $13 \mathrm{~s}$ while their toxic effect was comparable with the untreated composites cured for $300 \mathrm{~s}$ regardless of the aging times.

\section{Identification of leachables}

The fractions of UDMA monomer and uncured UDMA polymer mixtures as a function of retention time obtained from the HPLC analysis are shown in Figure 5. Peaks of six major fractions (1 to 6) are shown for the UDMA monomer and two additional fractions ( $1^{\prime}$ and $2^{\prime}$ ) are shown for the uncured UDMA polymer mixture. The common retention time for the peaks were $3.5,6.3,10.3,16.2,21.5$, and $24.0 \mathrm{~min}$, while the additional peaks were eluted at 2.5 and $7.7 \mathrm{~min}$. These two additional peaks are characteristic of DMAEMA and CQ, respectively.

The amount of material extracted from the polymerized composite powder was $1.12(0.1) \%$, and retention times of its fractions determined from the HPLC

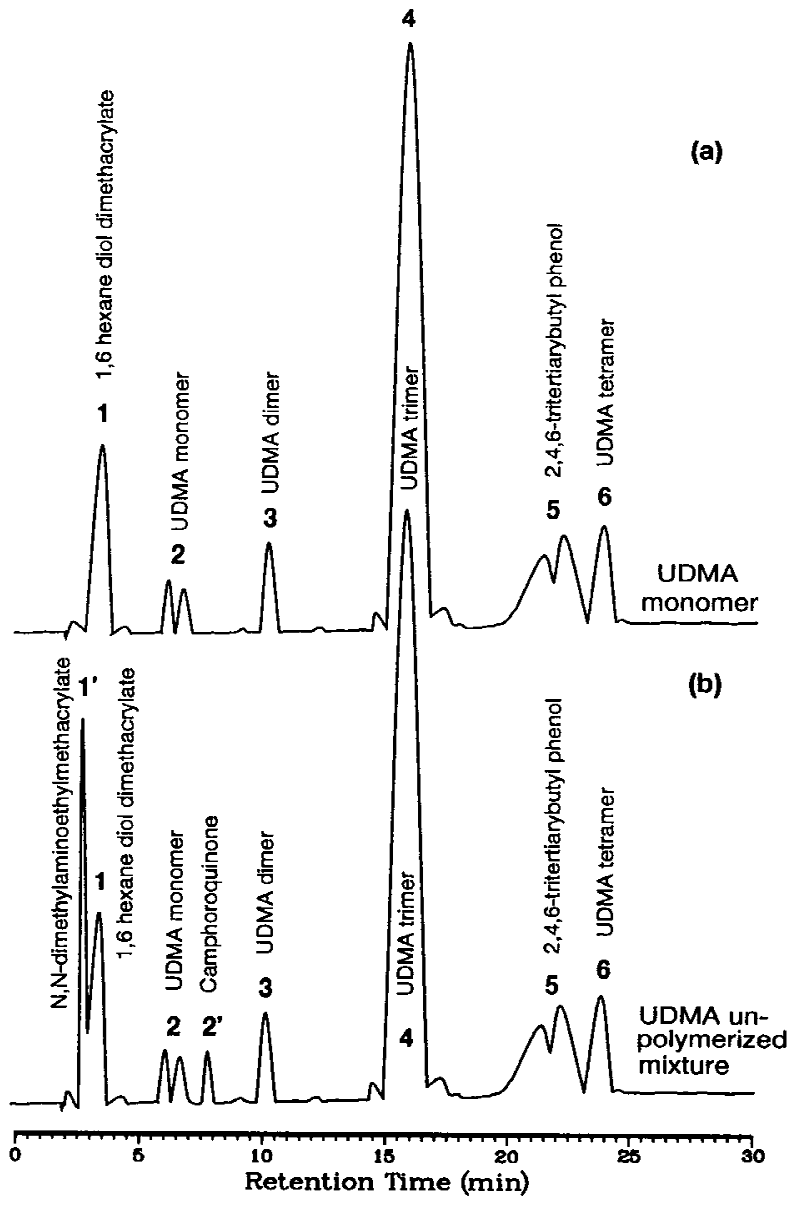

Figure 5. High performance liquid chromatographs of (a) UDMA monomer and (b) uncured UDMA polymer mixture.

analysis are shown in Figure 6(b). A magnification of the fraction peaks is shown in Figure 6(c). The extracted components showed three main features: (a) the major component was retained at 16.2 min (peak 4); (b) the peak retained at 2.5 min (peak $1^{\prime}$ ) in the unpolymerized UDMA mixture did not exist in the extract; and (c) the peak retained at $7.7 \mathrm{~min}$ (peak 2') appeared small.

The mass spectrum of UDMA monomer is shown in Figure 7. The spectrum of the UDMA monomer showed a clear peak, which corresponded to the molecular ion of UDMA that has a mass to charge ratio $(\mathrm{m} / \mathrm{e})$ of 471 . The molecular weight of 471 is close to that of the monomer $(470 \mathrm{gm} / \mathrm{mole})$. The spectrum also showed fragment ion peaks of propene or secondary amine $(\mathrm{m} / \mathrm{e}=41)$, primary amide or primary amine $(\mathrm{m} / \mathrm{e}=44)$, propene ketone $(\mathrm{m} / \mathrm{e}=55)$, 2 methyl propene ketone $(\mathrm{m} / \mathrm{e}=69), 2$-methyl propene ethyl ester $(\mathrm{m} / \mathrm{e}=113)$, and 1,3-methyl 5-hexene 2amide $(\mathrm{m} / \mathrm{e}=154)$.

The spectra of chromatographic fractions 1, 2, 4, and 5 of the $75 \%$ ethanol/water extract fractions for the 30-s cured composite are shown in Figures 8-11, respectively. The m/e of fraction 1 of the extract (Fig. 8) 


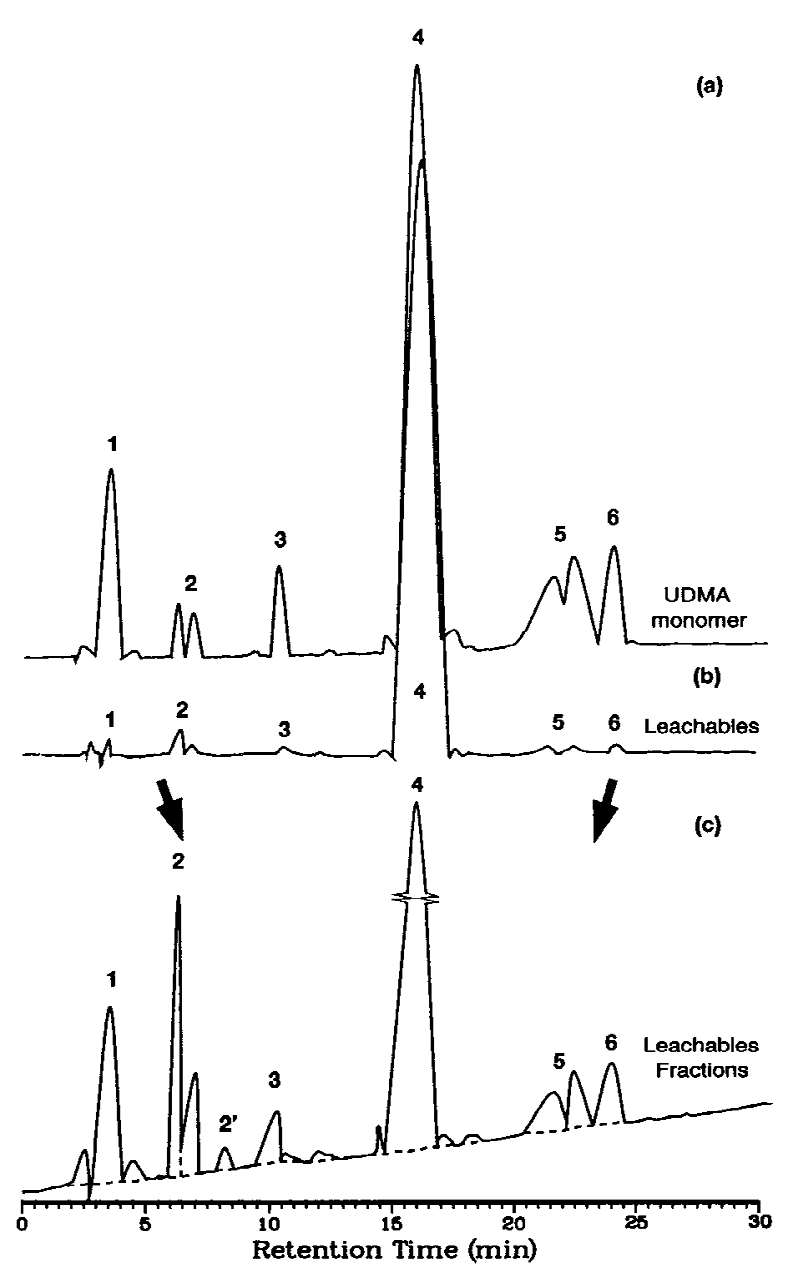

Figure 6. High performance liquid chromatographs of (a) UDMA monomer, (b) leachables from UDMA-based composites extracted from 75\% ethanol-water, and (c) a magnification of minor peaks of the leachables.

eluted at 3.5 min was 252, which corresponded to 1,6 hexane diol dimethacrylate molecular weight, while the highest $\mathrm{m} / \mathrm{e}$ value of $764 \mathrm{gm} / \mathrm{mole}$ corresponded to the molecular ion of 1,6 hexane diol dimethacrylate trimer. The $\mathrm{m} / \mathrm{e}$ peaks showed fragmentation patterns that supported this identification, namely, the m/e peaks that occurred at $57,71,83$, and 111 , which corresponded to 1-propanone, 1-butanone, 1-hexene, and dipropyl ester, respectively, which are constituents of 1,6 hexane diol dimethacrylate comonomer. The mass spectrum of fraction 2' of the extract (Fig. 9) showed a primary $\mathrm{m}$ /e peak of 170 , which is equal to the molecular weight of CQ. The mass spectrum of the major component eluted at $16.2 \mathrm{~min}$ (fraction 4) showed m/e (Fig. 10) peaks corresponding to the UDMA monomer and trimer where the characteristic m/e peaks occurred at 113, 154, 471, and 697. This spectrum is not identical with Figure 7 because it is an extract and not the pure UDMA. The main m/e peak in the mass spectrum of fraction 5 (Fig. 11) occurred at 261, which is the molecular ion of 2,4,6-tritertiarybutyl phenol.

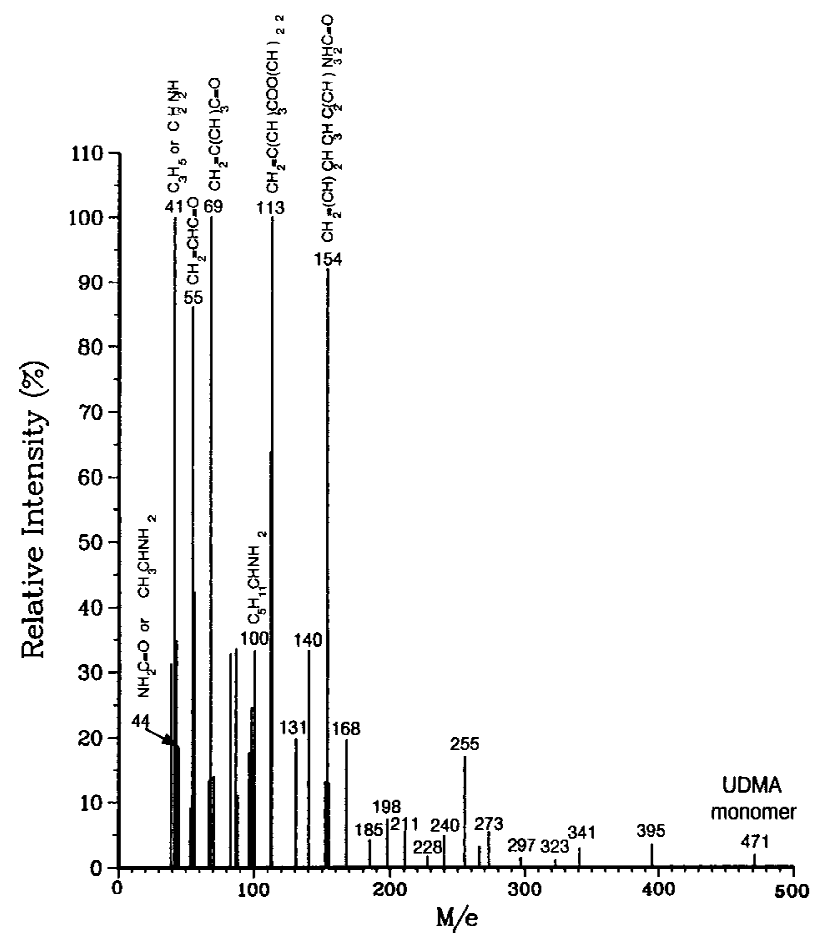

Figure 7. Mass spectrum of UDMA monomer diluted with $75 \%$ ethanol-water.

\section{DISCUSSION}

The percent metabolism of cells in vitro for untreated or polished composites (Figs. 1 and 2) correlate their biocompatibility with curing time of the composites by visible light and postcuring time (aging) with heat to ensure maximum polymerization. These data

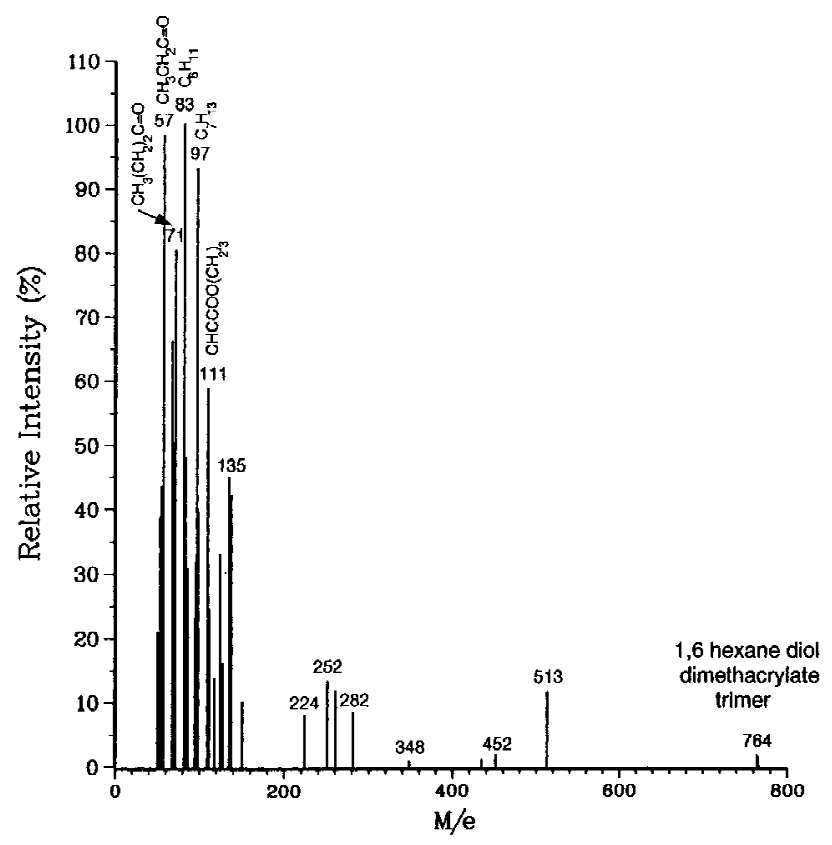

Figure 8. Mass spectrum of fraction \#1 of leachables extracted by $75 \%$ ethanol-water with retention time of $3.5 \mathrm{~min}$. 


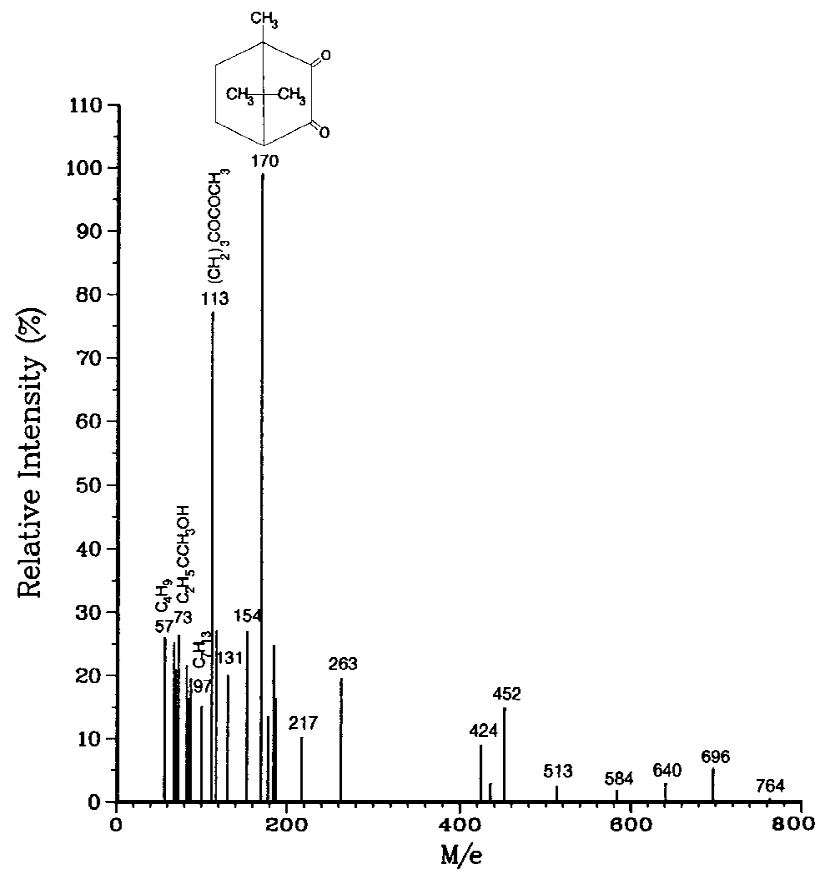

Figure 9. Mass spectrum of fraction \#2' of leachables extracted by $75 \%$ ethanol-water with retention time of $6.3 \mathrm{~min}$.

show that curing the composite for a minimum of 150 $\mathrm{s}$ and postcuring it for $24 \mathrm{~h}$ at $57^{\circ} \mathrm{C}$ is required to give comparable biocompatibility of the restorative composite to the negative control.

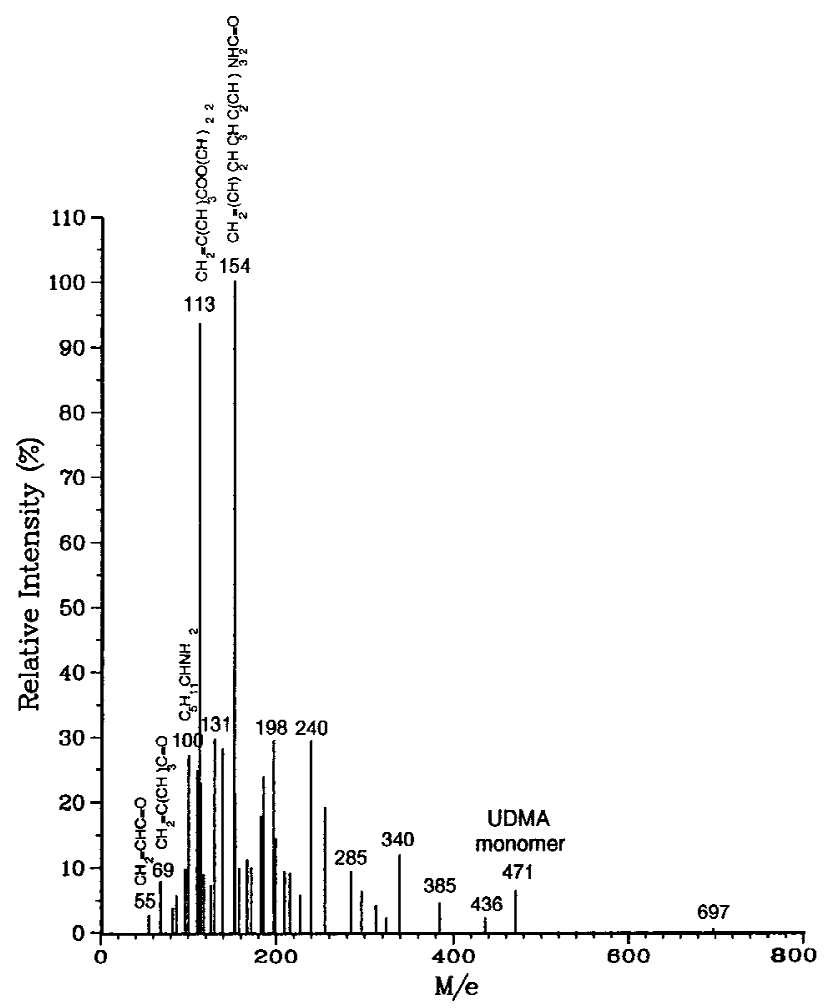

Figure 10. Mass spectrum of fraction \#4 of leachables extracted by $75 \%$ ethanol-water with retention time of 16.2 $\min$.

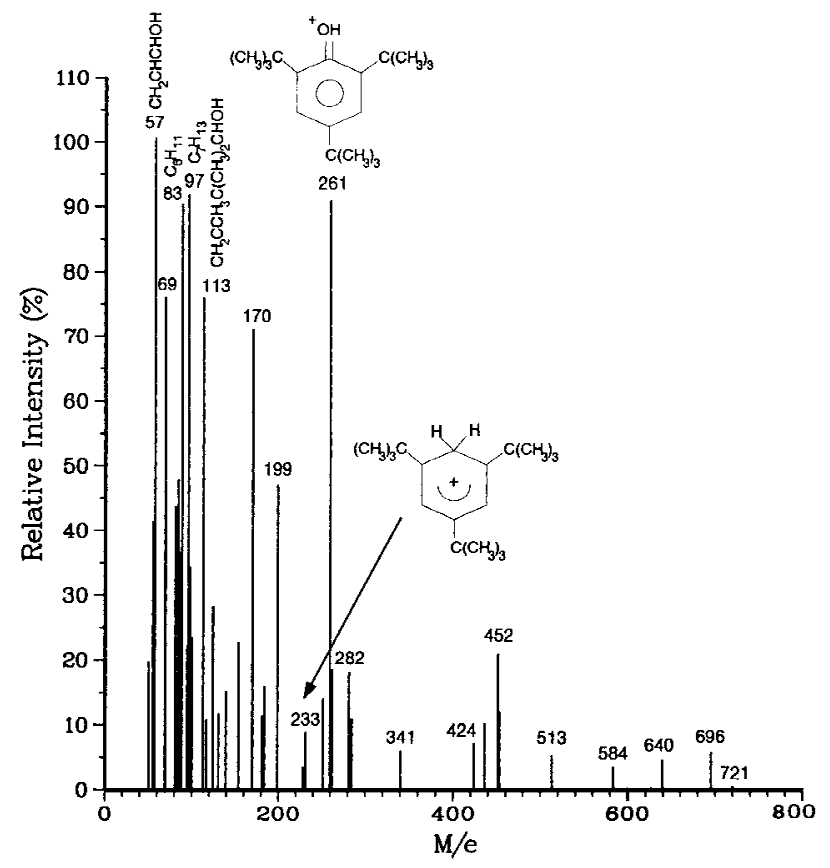

Figure 11. Mass spectrum of fraction \#5 of leachables extracted by $75 \%$ ethanol-water with retention time of 21.5 min.

The in vitro cell culture results indicate that curing the composites by visible light up to $300 \mathrm{~s}$ but without postcuring did not decrease the cytotoxic effects of the composite nor make them biocompatible with the cells if they were not extracted by either water or $75 \%$ ethanol-water. This incompatibility may be related to the capability of the resin to release organic components, which consist of residuals of uncured monomers and oligomers. The explanation is consistent with the observations of Rathbun et al., ${ }^{8}$ who showed that extraction of composites with organic solvents to remove the unreacted species reduced their cytotoxicity by $90 \%$. The explanation also is supported by $L D_{50}$ values for the various components of the resins that exerted cytotoxic effects on the Balb/c 3T3 cells. ${ }^{16}$

Since higher exposure time of the composite to light increases the depth of cure, ${ }^{17,18}$ and thus increases the hardness of composites, which also correlates well with the degree of conversion, ${ }^{19,20}$ one would assume higher biocompatibility with higher exposure time. However, it was surprising that composites that were untreated or water extracted and cured with visible light for $300 \mathrm{~s}$ without aging were comparable or worse in biocompatibility than the same categories cured for $13 \mathrm{~s}$. This effect may be attributed to the presence of unreacted double bonds at the surface of the composites due to an oxygen-inhibited layer rendering it toxic even though it was exposed to light for a longer period. This observation is supported by the increase in the biocompatibility when the samples were polished (Fig. 2). Such an explanation is sup- 
ported by Vankerchoven et al., ${ }^{21}$ who found that polishing composites caused an important decrease in the quantity of the double bonds due to its thermal effect.

Aging of the composites by heating increases the degree of polymerization, ${ }^{22}$ thus decreasing the percentage of residual double bonds and increasing the crosslinking of the polymer network. Thus aging decreases the diffusion of low molecular weight molecules and limits the number of molecules available for leaching into solvents or into cell culture. Such a decrease was reflected by marked improvement of the biocompatibility in the composites and the decrease in the percent of leachables at longer aging times.

The cytotoxicity evaluation showed that extraction of composites with a $75 \%$ ethanol-water mixture improved the biocompatibility more than extraction of the composites with water alone, which agrees with the findings of Ferracane and Condon. ${ }^{13}$ This indicated that the ethanol-water mixture extracted more unbound low molecular weight extractables due to its ability to penetrate the polymerized resin network and swell it more effectively than water. However, when the composites were cured for short periods of time, the mean values for the percent leachables were lower but not statistically different for samples extracted with the ethanol mixture than for those extracted by water. For instance, the percent leachables were found to be $1.1(0.13) \%$ and $1.5(0.68) \%$ in $75 \%$ ethanol-water and water extractants, respectively, when the composites were cured for $13 \mathrm{~s}$ and postcured for $144 \mathrm{~h}$. Such a contradiction indicates that not all of the solvent sorbed by the resin had been eliminated by desiccation. This was apparent from negative values of the percent leachables that resulted for composites cured and postcured at $30 \mathrm{~s}$ and $0 \mathrm{~h}$, respectively. This effect was greater in the $75 \%$ ethanol-water mixture, which suggests that ethanol, being a better solvent for the UDMA composites, has a greater ability to bind to the polar groups in the resin than does water. This resulted in a greater gain of weight for the composites as compared to weight gain that took place in water; thus the net amount of leachables was less in the composites extracted by the ethanol mixture. This observation also was noted by Ferracane and coworkers, ${ }^{13}$ who gave a similar explanation.

$75 \%$ ethanol-water extraction of composites cured for 30 and $300 \mathrm{~s}$ with visible light and with $0 \mathrm{~h}$ of aging improved the biocompatibility from 47 to $74 \%$ compared with comparable untreated composites, while water extraction of the composites increased the compatibility only from 7 to $11 \%$. The polished composites, on the other hand, improved the biocompatibility compared to untreated composites from 27 to $33 \%$ when cured for 30 to $300 \mathrm{~s}$, respectively. Thus extracting the composites with $75 \%$ ethanol-water improved the biocompatibility more than removing the oxygeninhibited surface layer by polishing. These results in- dicate that the release of unpolymerized components from the bulk of composites as well as from the surface is responsible for cellular responses.

HPLC and mass spectroscopy of the leachable residues indicated that the major component released from the composites was the UDMA monomer and small quantities of fragments of this monomer, such as acrylic ester moieties. Mass spectroscopy of minor fractions of the extract revealed that 1,6 hexane diol methacrylate, camphoroquinone, and 2,4,6-tritertiarybutyl phenol were minor components. The methacrylate is used as a comonomer to reduce the viscosity and to increase the crosslinking of the polymer matrix while the camphoroquinone is used as a photochemical initiator. The phenol is included in the monomer system as an inhibitor to prevent premature polymerization.

\section{References}

1. H. Matsumoto, J. E. Gres, V. A. Marker, T. Okabe, J. L. Ferracane, and G. A. Harvey, "Depth of cure of visible light-cured resin: Clinical simulation," J. Prosthet. Dent., 55, 574-578 (1986).

2. L. Spangberg, H. Rodrigues, L. Langeland, and K. Langeland, "Biological effects of dental materials," Oral Surg., 36, 713-724 (1973).

3. D. A. F. Anderson, J. L. Ferracane, and E. R. Zimmermann. "Cytotoxicity of combinations of dental composites components," J. Dent. Res., 66, 133 [Abstract] (1987).

4. D. A. F. Anderson, E. R. Zimmermann, J. L. Ferracane, and M. Kaga, "Cytotoxicity of variably cured light-activated dental composites," J. Dent. Res., 67, 226 [Abstract] (1988).

5. M. Tobias, C. Edmund, F. R. Shiere, and R. E. Clark, "Pulpal reaction to a resin-bonded quartz composite material," J. Dent. Res., 52, 1281-1286 (1973).

6. C. T. Hanks, M. Anderson, and R. G. Craig, "Cytotoxic effects of dental cements on two-cell culture systems," J. Oral Pathol., 10, 101-112 (1981).

7. W. F. Caughman, G. B. Caughman, W. T. Dominy, and G.S. Schuster, "Cellular responses to glass ionomer and composite resin cements," J. Dent. Res., 68, 346 [Abstract] (1989).

8. M. A. Rathbun, R. G. Craig, C. T. Hanks, and F. E. Filisko, “Cytotoxicity of bis-GMA dental composite before and after leaching in organic solvents," J. Biomed. Mater. Res., 25, 443-457 (1991).

9. H. R. Stanley, R. L. Bowen, and J. Folio, "Compatibility of various materials with oral tissues. II. Responses to composite ingredients," J. Dent. Res., 58, 1507-1517 (1979).

10. M. Brännström and H. Nyborg, "Pulpal reaction to composite resin restorations," J. Prosthet. Dent., 27, 181-189 (1972).

11. S. Inokoshi, M. Iwaku, and T. Fusayama, "Pulpal response to a new adhesive restorative resin," J. Dent. Res., 61, 1014-1019 (1982).

12. C. F. Cox, C. L. Keall, H. J. Keall, E. Ostro, and G. Bergenholtz, "Biocompatibility of surface-sealed dental materials against exposed pulps," J. Prosthet. Dent., 57, 1-8 (1987).

13. J. L. Ferracane and J. R. Condon, "Rate of elution of leachable components from composite," Dent. Mater., 6, 282-287 (1990).

14. N. M. Mohsen and R. G. Craig, "Effect of silanation of fillers on their dispersability by monomer systems," J. Oral Rehab., 22, 183-189 (1995)

15. W. H. Douglas, R. G. Craig, and C. C. Chen, "A new composite 
restorative based on a hydrophobic matrix," J. Dent. Res., 58, 1981-1985 (1979).

16. C. T. Hanks, S. E. Strawn, J. C. Wataha, and R. G. Craig, "Cytotoxic effects of resin components on cultured mammalian fibroblasts," J. Dent. Res., 70, 1450-1455 (1991).

17. W. D. Cook, "Depth of cure in the UV photopolymerization of dimethacrylate-based dental filling materials," J. Macromol. Sci. Chem., A17, 99-111 (1982).

18. W. D. Cook and P. M. Standish, "Cure of resin-based restorative materials. II. White light photopolymerization resins," Aust. Dent. J., 28, 307-311 (1983).
19. J. L. Ferracane, "Correlation between hardness and degree of conversion during the setting reaction of unfilled dental restorative resins," Dent. Mater., 1, 11-14 (1985).

20. F. A. Rueggeberg, "Correlation of parameters used to estimate monomer conversion in a light-cured composite," J. Dent. Res. 67, 932-937 (1988).

21. H. Vankerchoven, P. Lambrechts, M. Van Beylen, C. L. Davidson, and G. Vanherle, "Unreacted methacrylate groups on the surfaces of composite resins," J. Dent. Res., 61, 791-795 (1982).

22. W. Wu, "Degree of cure and wear resistance of dental composites," J. Dent. Res., 62, 26 [Abstract] (1983). 